\title{
Non-muscle myosin Ila heavy chain links squamous-cell carcinoma of the head and neck to the DNA damage response
}

\author{
David R. Raleigh' and Daphne A. Haas-Kogan ${ }^{1,2}$ * \\ 1 Department of Radiation Oncology, University of California San Francisco, San Francisco, CA, USA \\ 2 Helen Diller Family Comprehensive Cancer Center, San Francisco, CA, USA \\ *Correspondence: dhaaskogan@radonc.ucsf.edu \\ Edited by: \\ Adam Paul Dicker, Thomas Jefferson University, USA \\ Reviewed by: \\ Timur Mitin, Massachusetts General Hospital, USA
}

Keyword: myosin lla

\section{A commentary on}

Direct in vivo RNAi screen unveils myosin IIa as a tumor suppressor of squamous cell carcinomas

by Schramek D, Sendoel A, Segal JP, Beronja

$S$, Heller E, Oristian D, Reva B, Fuchs

E. Science (2014) 343:309-13. doi:10.1126/

science. 1248627

The incidence of squamous cell carcinoma of the head and neck (HNSCC) reaches as high as 16.5 cases per 100,000 individuals in the United States (1). Earlystage lesions have a favorable prognosis when treated surgically, but approximately two-thirds of HNSCC are diagnosed at an advanced locoregional stage (2). Chemoradiation is the backbone of treatment for the majority of advanced tumors, and is associated with up to $80 \%$ long-term survival for patients with positive prognostic features (3). Notably, the success of genotoxic therapy for advanced HNSCC far exceeds non-surgical control rates for the majority of epithelial tumors. Moreover, the primary benefit from chemotherapy for HNSCC is conferred not through a decrease in distant metastases but through enhanced local control $(4,5)$. As such, significant efforts have been dedicated to elucidating the molecular drivers of HNSCC genesis and identifying the pathways that sensitize these malignancies to the effects of chemoradiation.

Infection with high-risk human papilloma virus (HPV) subtypes has emerged as an important risk factor for HNSCC. Unlike lesions associated with excessive tobacco and alcohol use, TP53 mutations are rarely found in HPV-positive HNSCC, which is generally associated with a favorable clinical course (6). Despite this association, no targeted therapies against HPV oncogenes are available for the treatment of patients with HNSCC. Similarly, genetic and epigenetic aberrations of the H-RAS, NOTCH, PI3K/Akt, BRCA1, and TGF- $\beta$ pathways have also been associated with HNSCC, but targeted agents remain in preclinical stages for HNSCC (2). In contrast, epidermal growth factor receptor (EGFR) inhibition combined with radiotherapy is an effective strategy for HNSCC (7). EGFR is upregulated in approximately $90 \%$ of HNSCCs, and expression level is an independent determinant for decreased survival and impaired locoregional control $(8,9)$. However, EGFR inhibitors as monotherapy have produced only modest clinical outcomes, and survival from HNSCC has not improved in recent decades. Consequently, enhanced understanding of the molecular carcinogenesis of HNSCC is required to facilitate development of new treatments.

Using an in vivo RNA interference (RNAi) strategy to screen for driver mutations involved in tumorigenesis, Schramek and colleagues recently reported a novel link between cutaneous squamous-cell carcinoma (CSCC), HNSCC, and impaired DNA damage response (DDR) signaling (10). To do so, a lentivirus-mediated RNAi library was selectively delivered to the surface ectoderm in utero under ultrasound guidance in a TGF- $\beta$-receptor-II conditional knockout murine model of
CSSC and HNSCC. Selection of multiple independent small hairpin RNAs (shRNAs) in three or more tumors yielded eight potential tumor suppressors. Among these lesions, $40 \%$ were enriched with shRNAs against $M y h 9$, which encodes nonmuscle myosin IIa heavy chain. When conditionally suppressed in mice with endogenous TGF- $\beta$ signaling, loss of myosin IIa was sufficient for development of CSCC, albeit with a significantly longer latency. By activating the DDR pathway, Schramek et al. further demonstrate that both myosin IIa suppression and small molecule inhibition delay and reduce p53 activation in response to double strand breaks. Consistently, loss of myosin IIa reduces the expression of p53-responsive genes, including $p 21, \mathrm{Fas}, \mathrm{Bax}, \mathrm{Mdm} 2$, and

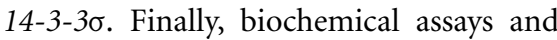
microscopy both indicate that $\mathrm{p} 53$ fails to accumulate and/or remain in the nucleus in the absence of endogenous myosin IIa activity.

These findings suggest a new role for myosin IIa as a tumor suppressor that facilitates the DDR through stabilization of p53 in the nucleus. Although the present data pertain to CSSC and HNSCC, it is intriguing to consider a broader role for myosin IIa in oncogenesis and the DDR. Also notable from this work is the non-invasive, ultrasound-guided method of selective shRNA delivery in utero. This novel technique circumvents the immunological and physiological confounders of orthotopic transplantation, and stands to have broad applications for future genetics screens. However, hairpin efficiency is a 
central component of RNAi and may bias data away from biological reality. Consistent with this limitation, TP53, which is frequently mutated in HNSCC, was not identified as a carcinogenic driver in the present study, presumably secondary to hairpin inefficiency.

Despite the abundance of murine data presented by Schramek et al., the pathophysiological relevance of Myh9 loss for human malignancy remains uncertain. In this regard, approximately $80 \%$ of myosin IIa null HNSCCs in humans show concomitant loss of the TGF- $\beta$ pathway, suggesting that myosin IIa loss may not be a direct oncogenic driver (10). Furthermore, a mere $30-40 \%$ of mice with intact TGF- $\beta$ signaling develop tumors following Myh9 suppression and only do so after a mean latency of 1 year. Indeed, less than one-quarter of human SCCs and fewer than one-third of human HNSCCs show weak or absent immunolabeling for myosin IIa. Therefore, rather than functioning as a primary oncogenic driver in human malignancy, Myh9 mutation may play an accessory role in the genesis or progression of certain HNSCC subsets. In sum, it is likely that inactivating mutations of myosin IIa have a low penetrance in human HNSCC, as was suggested by the initial sequencing effort that identified a link between Myh9 and HNSCC (11). Nevertheless, these results provide compelling evidence that aberrant activity of the DDR is associated with HNSCC and further support the hypothesis that these tumors are both biologically and genetically diverse. Further studies are necessary to establish whether Myh9 mutation is of robust prognostic significance and if DDR pathways can be manipulated to enhance the efficacy of treatment for HNSCC.

\section{REFERENCES}

1. Edwards BK, Noone AM, Mariotto AB, Simard EP, Boscoe FP, Henley SJ, et al. Annual report to the nation on the status of cancer, 1975-2010, featuring prevalence of comorbidity and impact on survival among persons with lung, colorectal, breast, or prostate cancer. Cancer (2013) 120(9):1290-314. doi:10.1002/cncr.28509

2. Leemans CR, Braakhuis BJM, Brakenhoff RH. The molecular biology of head and neck cancer. Nat Rev Cancer (2011) 11:9-22. doi:10.1038/ nrc2982-c2

3. Ang KK, Harris J, Wheeler R, Weber R, Rosenthal DI, Nguyen-Tân PF, et al. Human papillomavirus and survival of patients with oropharyngeal cancer. N Engl J Med (2010) 363:24-35. doi:10.1056/NEJMoa0912217

4. Adelstein DJ, Li Y, Adams GL, Wagner H Jr, Kish JA, Ensley JF, et al. An intergroup phase III comparison of standard radiation therapy and two schedules of concurrent chemoradiotherapy in patients with unresectable squamous cell head and neck cancer. J Clin Oncol (2003) 21:92-8. doi:10.1200/ JCO.2003.01.008

5. Denis F, Garaud P, Bardet E, Alfonsi M, Sire C, Germain T, et al. Final results of the 94-01 French Head and Neck Oncology and Radiotherapy Group randomized trial comparing radiotherapy alone with concomitant radiochemotherapy in advanced-stage oropharynx carcinoma. J Clin Oncol (2004) 22:69-76. doi:10.1200/JCO.2004.08. 021

6. Braakhuis BJ, Snijders PJ, Keune WJ, Meijer CJ, Ruijter-Schippers HJ, Leemans CR, et al. Genetic patterns in head and neck cancers that contain or lack transcriptionally active human papillomavirus. J Natl Cancer Inst (2004) 96:998-1006. doi:10.1093/jnci/djh183

7. Bonner JA, Harari PM, Giralt J, Azarnia N, Shin DM, Cohen RB, et al. Radiotherapy plus cetuximab for squamous-cell carcinoma of the head and neck. $N$ Engl J Med (2006) 354:567-78. doi:10.1056/ NEJMoa053422

8. Kalyankrishna S, Grandis JR. Epidermal growth factor receptor biology in head and neck cancer. J Clin Oncol (2006) 24:2666-72. doi:10.1200/JCO. 2005.04.8306

9. Ang KK, Berkey BA, Tu X, Zhang HZ, Katz R, Hammond $\mathrm{EH}$, et al. Impact of epidermal growth factor receptor expression on survival and pattern of relapse in patients with advanced head and neck carcinoma. Cancer Res (2002) 62:7350-6.

10. Schramek D, Sendoel A, Segal JP, Beronja S, Heller E, Oristian D, et al. Direct in vivo RNAi screen unveils myosin IIa as a tumor suppressor of squamous cell carcinomas. Science (2014) 343:309-13. doi:10.1126/science.1248627

11. Stransky N, Egloff AM, Tward AD, Kostic AD, Cibulskis K, Sivachenko A, et al. The mutational landscape of head and neck squamous cell carcinoma. Science (2011) 333:1157-60. doi:10.1126/ science. 1208130

Conflict of Interest Statement: The authors declare that the research was conducted in the absence of any commercial or financial relationships that could be construed as a potential conflict of interest.

Received: 14 July 2014; accepted: 07 August 2014; published online: 25 August 2014.

Citation: Raleigh DR and Haas-Kogan DA (2014) Nonmuscle myosin IIa heavy chain links squamous-cell carcinoma of the head and neck to the DNA damage response. Front. Oncol. 4:228. doi: 10.3389/fonc.2014.00228

This article was submitted to Radiation Oncology, a section of the journal Frontiers in Oncology.

Copyright (c) 2014 Raleigh and Haas-Kogan. This is an open-access article distributed under the terms of the Creative Commons Attribution License (CC BY). The use, distribution or reproduction in other forums is permitted, provided the original author(s) or licensor are credited and that the original publication in this journal is cited, in accordance with accepted academic practice. No use, distribution or reproduction is permitted which does not comply with these terms. 